\title{
Luigi-Alberto Sanchi, Guillaume Budé et ses devanciers italiens: à propos des "Commentaires de la langue grecque"
}

\section{Filippo Fonio}

\section{(2) OpenEdition}

\section{Journals}

\section{Edizione digitale}

URL: http://journals.openedition.org/studifrancesi/35842

DOI: $10.4000 /$ studifrancesi.35842

ISSN: 2421-5856

\section{Editore}

Rosenberg \& Sellier

\section{Edizione cartacea}

Data di pubblicazione: 1 juillet 2005

Paginazione: 144

ISSN: 0039-2944

\section{Notizia bibliografica digitale}

Filippo Fonio, «Luigi-Alberto Sanchi, Guillaume Budé et ses devanciers italiens: à propos des "Commentaires de la langue grecque"», Studi Francesi [Online], 145 (XLIX | I) | 2005, online dal 30 novembre 2015, consultato il 18 avril 2021. URL: http://journals.openedition.org/studifrancesi/35842 ; DOI: https://doi.org/10.4000/studifrancesi.35842

Questo documento è stato generato automaticamente il 18 avril 2021.

\section{cc) $(9)$}

Studi Francesi è distribuita con Licenza Creative Commons Attribuzione - Non commerciale - Non opere derivate 4.0 Internazionale. 


\title{
Luigi-Alberto Sanchi, Guillaume Budé et ses devanciers italiens: à propos des "Commentaires de la langue grecque"
}

\author{
Filippo Fonio
}

\section{NOTIZIA}

LUIGI-ALBERTO SANCHI, Guillaume Budé et ses devanciers italiens: à propos des "Commentaires de la langue grecque”, «Bibliothèque d'Humanisme et Renaissance», LXV, 3 (2003), pp. 641-653.

1 Si possono riscontrare diversi precursori italiani dei Commentarii linguae Graecae di Guillaume Budé (1529), importante raccolta lessicografica antecedente il grande dizionario greco-latino di Henri Estienne, il Thesaurus grecae linguae (1572), al quale i Commentarii contribuiscono in misura non secondaria. L'opera di Budé, più volte riedita anche con le aggiunte del suo allievo Jacques Toussain, repertoria un gran numero di autori antichi (centonove greci, settantacinque latini) e di citazioni (ventimila). La materia è disposta in base a criteri prevalentemente di natura tematica, ricorrendo a un ordine alfabetico soltanto nell'indice collocato in fondo al volume. La trattazione è interrotta da numerosi excursus inerenti questioni erudite o grammaticali (non quindi riferiti alla realtà politica del tempo né a polemiche culturali, secondo un uso caro agli umanisti). Tali excursus sembrano ispirati fra l'altro dalla lettura delle Elegantiae di Lorenzo Valla. Oltre a Valla, le Centuriae di Poliziano e le Cornucopiae di Niccolò Perotti costituiscono alcuni dei modelli di Budé, opportunamente dissimulati per ragioni di orgoglio nazionale ma non trascurabili per quanto riguarda la messa a punto del metodo filologico, l'ordinamento della materia, gli excursus appunto. 